\title{
Entrepreneurial Leadership and Performance of Small and Medium Scale Enterprises in Benue State, Nigeria
}

Tsetim, James Tersoo ${ }^{1 *}$, Asenge Emmanuel Lubem ${ }^{2}$, ADUDU Chiangi Adudu ${ }^{1}$

${ }^{1}$ Federal University of Agriculture Makurdi, Benue State, Nigeria

${ }^{2}$ Benue State University Makurdi, Nigeria

DOI: $10.36347 /$ sjebm.2020.v07i04.002

| Received: 15.01.2020 | Accepted: 22.01.2020 | Published: 11.04.2020

*Corresponding author: Tsetim, James Tersoo

\section{Abstract}

Original Research Article

Entrepreneurial leadership has been tipped as one of the millennium solutions to challenges associated with the current competitive and dynamic global business environment. Majority of businesses operating in the localities of Benue state in Nigeria including Makurdi, the state capital are on small and medium scale. For decades now, Small and Medium Scale Enterprises (SMEs) are considered as an important aspect of Nigeria's economy and this makes it quite necessary to investigate the extent to which entrepreneurial leadership may boost performance of SMEs. Considering this fact, this study seeks to examine the effect of entrepreneurial leadership on performance of SMEs in Benue state, Nigeria. The study employed a quantitative survey research design. This study targeted a population of 708 owners/ managers who assume leadership positions in SMEs across Benue state. This number cuts across sectors like food processing, livestock rearing, trading, art/craft, bakery, table water, fashion and designing/hair dressing and ICT. Out of this figure 400 owners/managers were selected to represent the sample through purposive sampling technique. The data collection instrument for the study was a self-administered questionnaire Validity and reliability test were carried out on 30 employees from other organizations who were not part of the sample and through Cronbach's alpha the overall reliability co-efficient of 0.896 was obtained. The instrument was therefore considered consistent to be used in this study. The cleansed data was further quantitatively analyzed by product moment correlation and multiple regressions. Correlation was used to determine the magnitude of the relationship between entrepreneurial leadership and performance of SMEs while multiple regressions was used to test how leadership style explains changes in business performance of SMEs. Analysis was done with the aid of Statistical Package for Social Sciences (SPSS 21). Results of correlation analysis reveal that there is significant relationship between all the constructs of Entrepreneurial leadership (miner behavior, explorer behavior, accelerator behavior and integrator behavior) and performance of SMEs. The result of regression analysis showed that miner behavior, explorer behavior, accelerator behavior and integrator behavior jointly contribute to the observed change in SMEs performance. This study concludes that entrepreneurial leadership behaviors of managers/owners of SMEs significantly affect performance of such SMEs. Arising from the findings and conclusion, it is recommended amongst others that mangers/owners of SMEs avail themselves to available training options on how to effectively create and communicate vision as this is found to be a leadership behavior that positively correlates performance of SMEs.

Keywords: Entrepreneurial Leadership, SMEs Performance, Miner Behavior, Explorer Behavior, Accelerator Behavior, Integrator Behavior, Benue State.

Copyright @ 2020: This is an open-access article distributed under the terms of the Creative Commons Attribution license which permits unrestricted use, distribution, and reproduction in any medium for non-commercial use (NonCommercial, or CC-BY-NC) provided the original author and source are credited.

\section{INTRODUCTION}

\section{Background to the Study}

Successful leaders of Small and Medium Scale Enterprises (SMEs) build organizations that survive uncertainty, change, and competition. The continued influence of leaders on firm success can also be achieved by examining styles of leadership and the types of persons running the firms [1]. Failure of SMEs in early stages of their life cycle and stagnancy indicates poor business performance associated with leadership factor [2]. A leader leads himself and his followers by adopting some leadership styles depending on his own experience, background, education, or training. As much as there are different styles of leadership, each affects the level of performance within the firm [1]. The style with which the manager of a firm leads a venture influences its employees, customers, communities and other stakeholders [1]. 
The speed at which the economy is increasingly becoming unpredictable and competitively volatile in the dynamic global business environment required that business enterprises adopt an effective type of leadership that essentially differs from the classical business leadership concept and this style of leadership is entrepreneurial leadership [3]. Entrepreneurial leadership refers to a leadership style which focuses on influencing employees to manage resources strategically to stimulate opportunity and advantage-seeking behaviour [4]. An entrepreneurial leader employs the power of personal influence on employees and the leader (manager) of a firm has the legitimate authority to ensure that the firm achieves its purpose in the marketplace; therefore, entrepreneurial leadership style assumes greater chances of effectively managing the business entity than a mere manager who lacks status authority [3]. Determining what constitutes entrepreneurial leadership lies in how well a leader manages his general entrepreneurial leadership behavior, miner behavior, explorer behavior, accelerator behavior and integrator behavior $[5,6]$.

As of 2012, over 28 million small and medium scale businesses operated in the United States, United States Census Bureau, 2012a; 2012b. A year later, Global Alliance of SMEs [8] revealed that over $95 \%$ of the total number of enterprises in developed countries, like U.S, UK, Germany is SMEs. The report further stated that they account for over $50 \%$ of jobs and contribute to their GDP for more than 50\%. In the emerging economies like those of India, Brazil, Philippines, Malaysia, Hong Kong etc, over $90 \%$ of their business establishments are SME and they provide over $55 \%$ of total employment [9, 10]. In African countries; SMEs form $91 \%$ of formal businesses entities in South Africa, they form $70 \%$ of businesses in manufacturing sector in Nigeria and $92 \%$ of businesses in Ghana $[11,9]$.

SMEs play a fundamental role in nations' economy both in developed, emerging and developing economies [12]. They serve as a source of innovation, technological growth, and creation of new job [13]. And of course they connect the nations and societies to the larger global economy [14]. It is important to assess how the adoption of entrepreneurial leadership may affect the performance of SMEs. Over two decades, the federal and state governments have been promoting entrepreneurial activities in towns and rural areas in Nigeria with Benue state inclusive. The trend has continued in a number of countries where entrepreneurship is considered the major determinant of economic activities [15]. These polices have always emerged as results of academic writings as they are mostly suggested by renowned academicians and, more recently, by the experience of successful entrepreneurs. Given the high attention given to entrepreneurship in Nigeria and Benue state in particular, entrepreneurship is expected to be booming in Benue state, however, the opposite is the case.

Hann [11], in an attempt to solve this puzzle asserted that not all businesses succeed and the leadership behaviors of entrepreneurs influence the growth and development of their business. And this forms the reason for undertaking this study so as to review the effect of entrepreneurial leadership on SMEs Performance in Benue state, Nigeria. After stating the objectives of the study, the study conducted a review of past literatures which the view to developing research hypotheses, after which the methodology employed in conducting the research was elucidated. The results and discussion of findings and conclusion wrapped it up, pointing to the implication of findings to leadership of entrepreneurs and suggestions for future studies.

\section{LITERATURE REVIEW AND HYPOTHESES DEVELOPMENT \\ Entrepreneurial Leadership}

The importance of entrepreneurial leadership became unavoidably imperative upon the realization that management of an organisation could form a significant factor in triggering entrepreneurial behaviour in employees since they are in routing contact with employees [16, 17]. According to Tarabishy, Solomon, Fernald Jr., and Sashkin [18], the concept of entrepreneurial leadership is an offshoot the desire to handle the dynamic market which demands managers to be transformative, proactive as well as innovative when managing.

Entrepreneurial leadership style embraces communicating a vision in order to buy participation of employees, and at the same time taking risk, innovating, seizing opportunities, and managing change [19]. It is also referred to the action exhibited by managers of SMEs while planning, operating, monitoring and communicating subordinates as well scanning for opportunities, taking risk and having the mentality to achieve goals in spite of obstacles [20]. An entrepreneurial leader focuses on managing human and material resources of a firm by carrying subordinates along so as to ensure the required employee commitment to achieve performance [1]. Entrepreneurial leaders have exhibited their ability to stimulate innovation and identify hidden business opportunities even in uncertain environments $[21,22$, 19, 17].

On a contrary, Li, Bao and Jiang [8] alongside other researchers disagree with the reality of an entrepreneurial leadership style, stating that it is only a mix of all different kinds of leadership styles, like transformational [8], visionary [23] and transactional [24] leadership. This argument as indisputably as it appears does adequately falsify the position that entrepreneurial leadership is a distinct leadership style which particularly aims at encouraging entrepreneurial 
behaviour and attitudes at workplace and so differs from other leadership styles [17].

This study having harmonized the opinions of other authors defines entrepreneurial leadership as possessing and communicating the vision to motivate employees to recognize, improve and take advantage of opportunity in order to gain competitive benefit. This view supports Renko et al. [15] who defined entrepreneurial leadership as affecting and directing the performance of employees toward the achievement of organizational objectives that involve recognizing and exploiting entrepreneurial opportunities.

\section{Entrepreneurial Leadership Practices}

Different authors of entrepreneurship tried to put forward standard dimensions of entrepreneurial leadership. In ascertaining the challenges facing entrepreneurial leadership McGrath and MacMillan [19] and Lajin and Zainol [10] set five specific entrepreneurial leadership roles played in order to succeed in the challenged and globalized market situation. They include framing the challenge, absorbing uncertainty, path-clearing, building commitment and specifying limits. Borrowing from McGrath and MacMillan [5], Gupta et al. [19] grouped the five specific roles into two dimensions: scenario enactment (framing the challenge, absorbing uncertainty and path-clearing) and cast enactment (building commitment and specifying limits). Bindah [1] model of entrepreneurship behaviour and leadership style points out people-oriented and control -oriented leadership as indicators entrepreneurial leadership which are also fundamental to the entrepreneurial firm performance.

Amer [1] stated that entrepreneurial leadership has 6 aspects viz: risk taking, pro-activeness, innovativeness, autonomy, competitive aggressiveness and taking ownership. Al Mamun, et al. [18] laid emphasis on the perspectives of Man, Lau and Snape [25] and Renko, et al. [15] then suggested responsibility, accountability, analytical thinking, and emotional intelligence as constructs of immediate interest in examining the effect of entrepreneurial leadership on enterprise performance and sustainability. According to Supartha and Saraswaty [20], entrepreneurial leadership indicators are exemplary leadership, adhering to rules, transparency, and effective representation and increasing employees' welfare.

In explaining entrepreneurial leadership practices, Thornberry [5] harmonized three different leadership styles (transformational, transactional and charismatic) and developed his model of entrepreneurial leadership. The model comprises five dimensions which include: general entrepreneurial leadership behavior, miner behavior, explorer behavior, accelerator behavior and integrator behavior.
Dahiru and Pihie [6] asserted that entrepreneurial leadership is not synonymous with entrepreneurship. While the specific discipline of entrepreneurship and entrepreneurs focuses on creating new initiatives, entrepreneurial leaders are looking for opportunities outside of their new ventures [17]. This study therefore adopts Thornberry [5] five dimensional models in studying the effect of entrepreneurial leadership on the performance of SMEs in Benue state, Nigeria. This model was previously used by Dahiru and Pihie [6] to ascertain how entrepreneurial leadership can be modeled to achieve effectiveness of schools in Malaysia. However, this study focused on four dimensions viz: miner behavior, explorer behavior, accelerator behavior and integrator behavior. The authors argue that by the time a leader covers the last four dimensions, he might have covered what constitute the general entrepreneurial leadership behavior dimensions.

\section{Miner behaviour}

Entrepreneurial leaders who are miners target inward, they search for avenues to see and expose the hidden treasures that often stay untapped in the company's own operations and developments. They need much approval from the organization and have less individual control owing to the fact that they grab inner opportunities that require the organizational lines to be crossed [26]. Entrepreneur's miner behaviour encompasses his/her ability to analyse the work load and productivity of his/her employees, as well as supporting them to overcome their challenges at their own capacity [5]. Miner behaviour represents the entrepreneurial leaders' determination to accomplish his leadership responsibilities creatively, using innovative approaches to resolve difficulties and acknowledging all the stakeholders of the organization when making decisions [5].

\section{Accelerator behaviour}

Accelerator behaviour includes instigating employees for creative ideas, triggering them to increase their productivity using innovative methods and creating a empowering environment for them to try new strategies. Accelerator behaviour includes awakening employees for creative thinking, inspiring them to increase their job performances through inventive approaches and generating enabling environment for them to try new innovative methods [5].

\section{Explorer behaviour}

Explorer behaviour represents the entrepreneurial leaders' action in unveiling hidden opportunities for the MEs growth, developing creative policies for the firm's performance improvement and foreseeing an innovative future for the firm. Explorer behaviour is the leader's ability to motivate staff to imagine new and innovative approaches of developing the SME [5]. 


\section{Integrator behaviour}

Integrator behaviour is exhibited when the SME's vision is conveyed to the staff, motivating them to embark on entrepreneurial thinking as well as making available finances for actualizing innovative ideas. Integrator behaviour of an SME manager embraces transmitting information on new production/marketing trends, encouraging latest technologies, keeping the SME focused in its mission and supporting new managerial initiatives by providing a supportive environment for the initiatives to survive [5].

\section{Business Performance}

Researchers in the past have so far been able to agree on a standard scale of business performance of organizations however, they are yet to come to conclusion on how to measure performance of SMEs since most of them don not have records of their performance and the little that keep their records are reluctant to give out such data to researchers $[12,13]$. A host of surveys in Africa and other developing countries lamented the difficulty in obtaining data in line with the standard measures widely employed in the developed economies like profitability, Return on asset (ROA), Return on investment (ROI), Return on equity (ROE), etc. in measuring performance of SMEs [7, 27, 13, 12].

In regards to the above, we employed SMEs self-measurements constructs to measure business performance. These constructs include: SMEs' ability to achieve startup goals, its ability to provide secured job to employees and satisfaction with company's performance $[28,12]$.

\section{Entrepreneurial Leadership and Performance of SMEs}

Studies so far have mainly geared towards training and coaching employees to encourage entrepreneurial behaviour [16]. However, this study focuses on leading entrepreneurially to achieve the set goals of an SME.

Gupta et al. [19] found that entrepreneurial leadership is a globally recognized concept, however, more pronounced in Western nations. Entrepreneurial leaders are innovative; they are not risk averse, instead they manage risk to make sure the organization succeed [27]. In contributing to organizational performance, entrepreneurial leaders are anxious to achieve, and they seize on realistic opportunities, balancing exploration with being opportunistic [29]. Entrepreneurial leaders are most likely to spearhead innovation, they are not afraid to be assertive, independent and above all, curious to be alert to what happens in the firm and the surroundings [6].

Encouraging entrepreneurial behaviour in employees through communication of a vision which is an aspect of entrepreneurial leadership is extremely important for the success of SMEs [30, 17]. Mohtar and
Rahim [18] presented the idea of relationship between entrepreneurial leadership and organizational performance, stating that entrepreneur behavior is linked with firm performance. A survey of women owned SMEs in Dar es salaam, Tanzania showed that there is a significantly strong positive correlation between entrepreneurial leadership style and business performance of SMEs [13]. Other studies had paired entrepreneurial orientation with leadership attributes as constructs of measuring entrepreneurial leadership style. A lot of such studies also revealed that there is a positive relationship between entrepreneurial leadership and performance of SMEs [27, 24, 14].

That fervent determination from the leader in finding solutions to challenges through proper decision making which signifies miner behavior greatly contributes in sustaining general effectiveness of an organization [11]. In the same vein the accelerator behavior of entrepreneurial leader by way of being supportive to employees spurs them bring out the best in them which in a long run act as an impetus to performance of the firm [13]. When an entrepreneurial leader envision an innovative future for the organization (explorer behavior) then communicates it to employees and at the same time encourages them to bring out innovative ideas to actualize the bright future which he also makes money available to implement the ideas (integrator behavior), he positively contributes to the performance of the said organization [6]. The leadership style at start-up and the growth phases are same however; sustaining the performance of an SME through subsequent phases of business growth may require shuffling through different leadership behaviors to achieve the firm's desired performance [31]. It is in view of the foregoing that this puts forward the following null hypothesis:

HO$_{1}$ : There is no significant relationship between miner behavior of entrepreneurial leader and the performance of small and medium scale enterprises in Benue state, Nigeria

$\mathbf{H O}_{2}$ : There is no significant relationship between explorer behavior of entrepreneurial leader and the performance of small and medium scale enterprises in Benue state, Nigeria.

$\mathbf{H O}_{3}$ : There is no significant relationship between accelerator behavior of entrepreneurial leader and the performance of small and medium scale enterprises in Benue state, Nigeria.

$\mathbf{H O}_{4}$ : There is no significant relationship between integrator behavior of entrepreneurial leader and the performance of small and medium scale enterprises in Benue state, Nigeria.

\section{MATERIALS AND METHODS}

The study employed a quantitative survey research design to determine the relationship between entrepreneurial leadership and performance of Small and Medium Scale Enterprises in Benue State, Nigeria. 
To ascertain the relationship between the variables, this study targeted a population of 708 owners/ managers who assume leadership positions in SMEs across Benue state. This number cuts across sectors like food processing, livestock rearing, trading, art/craft, bakery, table water, fashion designing/hair dressing and ICT. Out of this figure 400 managers/leaders were selected to represent the sample through purposive sampling technique. The data collection instrument for the study was a self-administered questionnaire which comprised of two parts to assess the main variables for the study. The study adopted the five construct (general entrepreneurial behavior miner behavior, explorer behavior, accelerator behavior and integrator behavior) entrepreneurial leadership scale developed by Thornberry [5] previously used by Dahiru and Pihie [6]. However, the instrument was adopted with modifications and only four constructs (miner behavior, explorer behavior, accelerator behavior and integrator behavior) were used in this study. SMEs performance is measured using non-financial measures of SMEs (achieving start up goals, ability to provide secure job to employees and satisfaction with company's performance) as designed by Tat Keh, Mai Nguyen and Ping Ng [28]. The items were asked on a four-point Likert scale as follows: Strongly Disagree (1), Disagree (2), Agree (3) and Strongly Agree (4). A validity and reliability test was carried out on 30 employees from other organizations who were not part of the sample and through Cronbach's alpha the overall reliability coefficient of 0.896 was obtained. The instrument was therefore considered consistent to be used in this study. The cleansed data was further quantitatively analyzed by Pearson correlation and multiple regressions. Correlation was used to determine the magnitude and direction of the relationship between entrepreneurial leadership style and SMEs performance while multiple regressions was used to test how leadership style explains changes in business performance of SMEs. Hypotheses were tested at 0.05 level of significance. Analysis was done with the aid of Statistical Package for Social Sciences (SPSS 21).

\section{Model Specification}

The study was measured based on the independent variable (entrepreneurial leadership) and the dependent variable (SMEs performance). In this study, SMEs performance (SMEsP) is regarded as function of entrepreneurial leadership (EL).

$\mathrm{SMEsP}=\mathrm{f}(\mathrm{EL})$

Where;

SMEsP $=$ SMEs Performance (Dependent Variable)

$\mathrm{EL}=$ Entrepreneurial Leadership (Independent Variables)

In this vein, the implicit form of the regression model is specified as follows:

$\mathrm{SMEsP}=\mathrm{f}(\mathrm{MB}, \mathrm{EB}, \mathrm{AB}, \mathrm{IB})$

Where:

$\mathrm{MB}=$ Miner Behavior

$\mathrm{EB}=$ Explorer Behavior

$\mathrm{AB}=$ Accelerator Behavior

IB = Integrator Behavior

Thus, the explicit regression form of the model was stated as follows:

SMEsP $=b_{0}+b_{1} \mathrm{MB}+b_{2} \mathrm{~EB}+b_{3} \mathrm{AB}+b_{4} \mathrm{IB}+\varepsilon$ 3

Where:

$b_{0}=$ is the constant or intercept

$b_{1-4}=$ are parameter estimates

$\varepsilon=$ is the error components.

\section{RESULTS}

The results of the data analyzed for the study were presented on the basis of the hypotheses generated for the study.

\section{Correlations Analysis}

$\mathrm{HO}_{1}$ : There is no significant relationship between miner behavior of entrepreneurial leader and the performance of small and medium scale enterprises in Benue state, Nigeria.

Table-1: Relationship between entrepreneurial miner behavior and performance of SMEs

\begin{tabular}{|c|c|c|c|}
\hline \multicolumn{4}{|c|}{ Correlations } \\
\hline \multirow{2}{*}{ Miner Behavior } & Miner Behavior & SMEs Performance \\
\cline { 2 - 4 } & Pearson Correlation & 1 & $.968^{* *}$ \\
\cline { 2 - 4 } & Sig. (2-tailed) & & .000 \\
\cline { 2 - 4 } SMEs Performance & N & 347 & 347 \\
\cline { 2 - 4 } & Pearson Correlation & $.968^{* *}$ & 1 \\
\cline { 2 - 4 } & Sig. (2-tailed) & .000 & 347 \\
\cline { 2 - 4 } & N & 347 & \\
\hline
\end{tabular}

Source: SPSS output, 2020.

Table 1 revealed the result of the hypothesis one stated above. Pearson correlation coefficient was carried out in order to present the relationship between miner behavior of entrepreneurial leader and the performance of small and medium scale enterprises in Benue state, Nigeria. The relationship between the two variables showed a positive correlation coefficient of 0.968** which exhibited a strong direct correlation 
between miner behavior of entrepreneurial leader and the performance of small and medium scale enterprises. Also, the two-tailed test conducted to access the significance level of the value of correlation coefficient yields a P-value of 0.000 which was significant at 0.05 level. Therefore, the hypothesis that states that there is no significant relationship between miner behavior of entrepreneurial leader and the performance of small and medium scale enterprises in Benue state, Nigeria was rejected, as the result implied that miner behavior of entrepreneurial leader was significantly related to the performance of small and medium scale enterprises in Benue state, Nigeria.

$\mathbf{H O}_{2}$ : There is no significant relationship between explorer behavior of entrepreneurial leader and the performance of small and medium scale enterprises in Benue state, Nigeria.

Table-2: Relationship between entrepreneurial Explorer behavior and performance of SMEs

\begin{tabular}{|c|c|c|c|}
\hline \multicolumn{4}{|c|}{ Correlations } \\
\hline & & Explorer Behavior & SMEs Performance \\
\hline \multirow{3}{*}{ Explorer Behavior } & Pearson Correlation & 1 & $.975 * *$ \\
\hline & Sig. (2-tailed) & & .000 \\
\hline & $\mathrm{N}$ & 347 & 347 \\
\hline \multirow[t]{3}{*}{ SMEs Performance } & Pearson Correlation & $.975 * *$ & 1 \\
\hline & Sig. (2-tailed) & .000 & \\
\hline & $\mathrm{N}$ & 347 & 347 \\
\hline
\end{tabular}

Table 2 showed the result of hypothesis 2 stated above. To test the hypothesis, the Pearson correlation coefficient was conducted to show the relationship between explorer behavior of entrepreneurial leader and the performance of small and medium scale enterprises. The relationship between the two variables revealed a positive correlation coefficient of $0.975^{* *}$ which indicates a strong direct correlation between explorer behavior of entrepreneurial leader and performance of small and medium scale enterprises in Benue state, Nigeria. Also, the two-tailed test conducted to ascertain the significance level of the value of correlation coefficient yields a P-value of 0.000 which was significant at 0.05 level. Therefore, the hypothesis that states there is no significant relationship between accelerator behavior of entrepreneurial leader and the performance of small and medium scale enterprises in Benue state, Nigeria was rejected, as the result indicated that explorer behavior of entrepreneurial leaders is significantly related to performance of small and medium scale enterprises.

$\mathbf{H O}_{3}$ : There is no significant relationship between accelerator behavior of entrepreneurial leader and the performance of small and medium scale enterprises in Benue state, Nigeria.

Table-3: Relationship between entrepreneurial accelerator behavior and performance of SMEs

\begin{tabular}{|c|c|c|c|}
\hline \multicolumn{4}{|c|}{ Correlations } \\
\hline & & Miner Behavior & SMEs Performance \\
\hline \multirow[t]{3}{*}{ Accelerator Behavior } & Pearson Correlation & 1 & $.965 * *$ \\
\hline & Sig. (2-tailed) & & .000 \\
\hline & $\mathrm{N}$ & 347 & 347 \\
\hline \multirow[t]{3}{*}{ SMEs Performance } & Pearson Correlation & $.965 * *$ & 1 \\
\hline & Sig. (2-tailed) & .000 & \\
\hline & $\mathrm{N}$ & 347 & 347 \\
\hline
\end{tabular}

Source: SPSS output, 2020.

Table 3 presented the result of hypothesis 2 stated above. In testing the hypothesis, the Pearson correlation coefficient was carried out to show the relationship of accelerator behavior of entrepreneurial leader and the performance of small and medium scale enterprises in Benue state, Nigeria. The relationship between the two variables revealed a positive correlation coefficient of $0.965 * *$ which represents a strong direct correlation between accelerator behavior of entrepreneurial leader and the performance of small and medium scale enterprises. Also, the two tailed test conducted to determine the significance level of the value of correlation coefficient yields a P-value of 0.000 which was significant at 0.05 levels. Therefore, the hypothesis that, accelerator behavior of entrepreneurial leader does not have significant relationship with performance of small and medium scale enterprises was rejected, as the result implies that accelerator behavior of entrepreneurial leader is 
Tsetim, James Tersoo et al., Sch J Econ Bus Manag, April., 2020; 7(4): 137-146

significantly related with performance of small and medium scale enterprises in Benue state, Nigeria.
$\mathbf{H O}_{4}$ : There is no significant relationship between integrator behavior of entrepreneurial leader and the performance of small and medium scale enterprises in Benue state, Nigeria.

Table-4: Relationship between entrepreneurial miner behavior and performance of SMEs

\begin{tabular}{|c|c|c|c|}
\hline \multicolumn{4}{|c|}{ Correlations } \\
\hline & & Integrator Behavior & SMEs Performance \\
\hline \multirow[t]{3}{*}{ Integrator Behavior } & Pearson Correlation & 1 & $.977 * *$ \\
\hline & Sig. (2-tailed) & & .000 \\
\hline & $\mathrm{N}$ & 347 & 347 \\
\hline \multirow[t]{3}{*}{ SMEs Performance } & Pearson Correlation & $.977 * *$ & 1 \\
\hline & Sig. (2-tailed) & .000 & \\
\hline & $\mathrm{N}$ & 347 & 347 \\
\hline
\end{tabular}

Source: SPSS output, 2020.

Hypothesis 4 above was tested by the Pearson Product Moment correlation statistical tool. On this note, the relationship between two variables (integrator behavior of entrepreneurial leader and the performance of small and medium scale enterprises) was found to be positive with a co-efficient of 0.977 implying a very strong relationship. Equally, the two tailed test conducted to check for the significance level of the value of correlation coefficient yields a P-value of 0.000 which was significant at 0.05 levels. Therefore, the hypothesis that states There is no significant relationship between integrator behavior of entrepreneurial leader and the performance of small and medium scale enterprises in Benue state, Nigeria was rejected, as the result implies that integrator behavior of entrepreneurial leader significantly relates with performance of small and medium scale enterprises.

\section{REGRESSION ANAL YSIS}

To further test each of the hypotheses formulated in the study, a multiple regression analysis was conducted to confirm the presence of relationship between the constructs of the study. The regression analysis can be used to forecast the values of a dependent variable given value of one or more independent variables by calculation of a regression equation. Therefore, a general model of the regression analysis is given below;

SMEsP $=\mathrm{f}(\mathrm{MB}, \mathrm{EB}, \mathrm{AB}, \mathrm{IB})$. While the explicit form of the model is SMEsP $=b_{0}+b_{1} \mathrm{MB}+b_{2} \mathrm{~EB}+$ $b_{3} \mathrm{AB}+b_{4} \mathrm{IB}+\varepsilon$

Table-5: Regression Model Summary and ANOVA to forecast the effect of Entrepreneurial leadership on SMEs Performance

\begin{tabular}{|l|l|c|c|c|c|c|}
\hline Model & \multicolumn{1}{|c|}{$\begin{array}{c}\text { Sum of } \\
\text { Squares }\end{array}$} & Df & Mean Square & F & Sig. \\
\hline \multirow{2}{*}{1} & Regression & 34.420 & 4 & 6.884 & 1412.319 & $.000^{\mathrm{b}}$ \\
\cline { 2 - 7 } & Residual & 1.331 & 342 & .005 & & \\
\cline { 2 - 7 } & Total & 35.751 & 346 & & & \\
\hline $\mathrm{R}=.981 \mathrm{a}$ \\
$\mathrm{R}$ Square $=.963$ \\
Adjusted R Square = .962 \\
Standard Error = .06982 \\
a. Dependent Variable: SMEs Performance \\
b. Predictors: (Constant), Integrator Behavior, Accelerator Behavior, Explorer Behavior, Miner \\
Behavior
\end{tabular}

Source: SPSS output, 2020.

The regression model summary and ANOVA in table 5 above indicates that the observed variance accounted for by four predictors (miner behavior, explorer behavior, accelerator behavior and integrator behavior) is $96.3 \%$. This connotes a strong and positive relationship between entrepreneurial leadership and SMEs performance which also confirm the previously tested correlation result of four sub-constructs of entrepreneurial leadership on SMEs performance. The result from the ANOVA statistics indicates that the processed data, which is the population parameters, had a significance level of 0.000 which shows that the data is ideal for making a conclusion on the population's parameter as the value of significance ( $p$-value) is less than $5 \%$ which indicates that the model was statistically significant as $(\mathrm{F}=1412.319 ; \mathrm{P}=0.000)$ is less than 
Tsetim, James Tersoo et al., Sch J Econ Bus Manag, April., 2020; 7(4): 137-146

0.005. This means that the four predictors (miner behavior, explorer behavior, accelerator behavior and integrator behavior) jointly contribute to the observed change in the dependent variable (SMEs Performance).

Table-6: Regression Coefficients ${ }^{\mathrm{a}}$

\begin{tabular}{|c|c|c|c|c|c|c|}
\hline \multirow[t]{2}{*}{ Model } & & \multicolumn{2}{|c|}{ Unstandardized Coefficients } & \multirow{2}{*}{$\frac{\text { Standardized Coefficients }}{\text { Beta }}$} & \multirow[t]{2}{*}{$\mathbf{T}$} & \multirow[t]{2}{*}{ Sig. } \\
\hline & & B & Std. Error & & & \\
\hline \multirow[t]{5}{*}{1} & (Constant) & 1.763 & .129 & & 13.668 & .000 \\
\hline & Miner Behavior & 288 & .044 & 607 & 6.554 & .000 \\
\hline & Explorer Behavior & .382 & .061 & 737 & 6.223 & .000 \\
\hline & Accelerator Behavior & 220 & .046 & .496 & .4 .741 & .000 \\
\hline & Integrator Behavior & 216 & .054 & .213 & 4.025 & .000 \\
\hline
\end{tabular}

Source: SPSS output, 2020.

Using the result of regression coefficient as presented in table 6 , the regression equation for this study $\left(\mathrm{SMEsP}=b_{0}+b_{1} \mathrm{MB}+b_{2} \mathrm{~EB}+b_{3} \mathrm{AB}+b_{4} \mathrm{IB}+\right.$ $\varepsilon)$ can be substituted thus: SMEsP $=1.76+.288+.382$ $+.220+.216$. This shows that all the four predictor variables contribute significantly to Performance of SMEs. It is evident from the table that explorer behavior: $\beta=.737$; $(279)=6.223, \mathrm{p}(.000)<0.05$ and miner behavior: $\beta=.607$; $\mathrm{t}(279)=6.554, \mathrm{p}(.000)<$ 0.05 contribute more significantly to performance of SMEs. Then they are closely followed by accelerator behavior: $\beta=.496$; $\mathrm{t}(279)=4.741, \mathrm{p}(.000)<0.05$; and integrator behavior: $\beta=.213 ; \mathrm{t}(279)=4.025, \mathrm{p}(.000)<$ 0.05 which also contribute significantly to performance of SMEs. This implies that for every unit increase in performance of SMEs, there has been a corresponding increase of.737, .607, .496 and .213 from explorer behavior, miner behavior, accelerator behavior, integrator behavior respectively.

\section{DISCUSSION}

With regards to the hypothesis one which states that there is no significant relationship between miner behavior of entrepreneurial leader and the performance of small and medium scale enterprises in Benue state, Nigeria, the study discovered that miner behavior of entrepreneurial leader is significantly related to performance of small and medium scale enterprises in Benue state, Nigeria. This result is similar to the findings of Botha [8] which reveals that there is a statistically significant relationship between miner behavior and business performance. Also, the second hypothesis which states that there is no significant relationship between explorer behavior of entrepreneurial leader and the performance of small and medium scale enterprises in Benue state, Nigeria, the study found out that explorer behavior of entrepreneurial leader is significantly related to performance of small and medium scale enterprises in Benue state, Nigeria. This result is line with the findings of Othman and Yee [31] which indicated that the accelerator behavior of entrepreneurial leader by way of being supportive to employees spurs them to bring out the best in them which in a long run act as an impetus to performance of the firm.
Furthermore, with respect to the third hypothesis which states that there is no significant relationship between accelerator behavior of entrepreneurial leader and the performance of small and medium scale enterprises in Benue state, Nigeria, the result shows that a accelerator behavior of entrepreneurial leader has a significant influence on performance of small and medium scale enterprises in Benue state, Nigeria. Moreover, as touching the fourth hypothesis which states that There is no significant relationship between integrator behavior of entrepreneurial leader and the performance of small and medium scale enterprises in Benue state, Nigeria, the study discovered that integrator behavior of entrepreneurial leader has a significant influence on performance of small and medium scale enterprises in Benue state, Nigeria. These two results are corroborated with the findings of Dahiru and Pihie [6] which revealed that when an entrepreneurial leader envision an innovative future for the organization (explorer behavior) then communicates it to employees and at the same time encourages them to bring out innovative ideas to actualize the bright future which he also makes money available to implement the ideas (integrator behavior), he positively contributes to the performance of the said organization. This finding is also in line with Ruvio, Rosenblatt, \& Hertz-Lazarowitz [30] and De Greef [17] which exhibited that encouraging entrepreneurial behavior in employees through communication of a vision which is an aspect of entrepreneurial leadership is extremely important for the success of SMEs.

Finally, the regression analysis shows that the observed variance is explained by the four subconstructs (miner behavior, explorer behavior, accelerator behavior and integrator behavior) jointly contribute to the observed change in the dependent variable (SMEs Performance). Also, the result of the R2 of 0.963 from the findings connotes that about $96.3 \%$ of the variation in SMEs Performance can be explained by the sub-constructs of entrepreneurial leadership, such as miner behavior, explorer behavior, accelerator behavior and integrator behavior, as the $\mathrm{R}$ value of 0.981 indicates that a strong and positive relationship is found between the two variables (i.e. entrepreneurial 
leadership and performance of SMEs). Therefore, since the F-sig. (p-value) of.000 is less than $\alpha(0.05)$, hence, a significant correlation is found between entrepreneurial leadership and performance of SMEs. This result is supported in the findings of Mgeni and Nayak [12] which showed that there is a significantly strong positive correlation between entrepreneurial leadership style and business performance of SMEs.

\section{IMPLICATION OF FINDINGS FOR PRACTICE}

For managers of Small and Medium Scale Enterprises, this article points to an indication that entrepreneurial leadership could reliably promote entrepreneurial behavior in subordinates, which could positively charge human resource of the SME. Results of the findings suggest that if employees are led in an entrepreneurial way, employees feel more at ease and actively participate. They take responsibility of decisions they are part of them so their zeal to achieve is triggered. Thus, for managers/owners of SMEs aiming to realize these outcomes, adopting entrepreneurial leadership style is the best option. The different dimensions of entrepreneurial behaviors discussed in this study would also inform and assist managers/owners of SMEs in realizing the qualities they are expected to possess in paddling the affairs of the SMEs in an entrepreneurial way.

\section{CONCLUSION AND RECOMMENDATIONS}

This study was undertaken to investigate the relationship between entrepreneurial leadership and performance of small and medium scale enterprises in Benue state, Nigeria. The findings and possible explanations for the subject matter have been extensively discussed. From the findings a positive relationship was found between entrepreneurial leadership and performance of small and medium scale enterprises in Benue state. This study therefore concludes that, entrepreneurial leadership behaviors of managers/owners of SMEs significantly affect performance of such SMEs. Arising from the findings and conclusion, it is recommended that mangers/owners of SMEs avail themselves to available training options on how to effectively create and communicate vision as this is found to be a leadership behavior that positively correlates performance of SMEs. This study also recommends that entrepreneurs to develop their ability to inspire followers and act as role models for followers, as well as refine their opportunity recognition, innovation, and creativity skills since this too significantly affects firm performance. Finally, it is recommended that entrepreneurs should seek out development opportunities to enhance their entrepreneurial leadership skills before and during a business venture.

\section{REFERENCES}

1. Amer H. Impact of Leadership Styles on Entrepreneurs' Business Success. Doctor of Philosophy (PhD), dissertation, STEM and
Professional Studies, Old Dominion University. 2017; Retrieved from https://digitalcommons.odu.edu/stemps_etds/22 (Accessed 5-12- 2019).

2. Zheltoukhova K, Suckley L. Hands-on or handsoff: Effective leadership and management in Small to Medium size Enterprises. Chartered Institute of Personnel and Development (CIPD). 2014.

3. Sandybayev, A. Impact of Effective Entrepreneurial Leadership Style on Organizational Performance: A Critical Review. International Journal of Economics and Management. 2019; 1(1): 47-55.

4. Ireland RD, Hitt MA, Sirmon DG. A model of Strategic Entrepreneurship: The Construct and its Dimensions. Journal of Management, 2003; 29(6): 963-989.

5. Thornberry N. Lead like an Entrepreneur: McGraw Hill Professional, 2006.

6. Dahiru AS, Pihie ZAL. Modeling of Entrepreneurial Leadership for Effectiveness of Schools. Middle-East Journal of Scientific Research. 2016; 24(4): 1371-1375.

7. Abu-Jarad YI, Yusof AN, Nikbin D. Organizational Culture and Organizational Performance. International Journal of Business and Social Science, 2010; 1(3): 12-21.

8. Global Alliance of SMEs. Four Global Experiences to Support SME Development. 2013; Retrieved@www.globalsms.org (Accessed 5-122019)

9. Zainol FA, Daud WNW, Abubakar LS, Shaari H, Halim HA. A Linkage between Entrepreneurial Leadership and SMEs Performance: An Integrated Review. International Journal of Academic Research in Business and Social Sciences, 2018; 8(4): 104-118.

10. Lajin NFM, Zainol FA. The Effect of Entrepreneurial Leadership, Self-Efficacy and Organizational Performance: A Conceptual Paper. International Academic Research Journal of Social Science, 2015; 1(1): 16-24.

11. Hann C. Epic fail. Entrepreneur, 2013; 41(1): 3436.

12. Mgeni TO, Nayak P. Impacts of Entrepreneurial Leadership Style on Business Performance of Female Owned SMEs in Dar es Salaam, Tanzania. Journal of Entrepreneurship \& Organization Management. 2015; 4(2): 39-40.

13. Mgeni TO. Impact of Entrepreneurial Leadership Style on Business Performance of SMEs in Tanzania. Journal of Entrepreneurship \& Organization Management. 2015; 4(2): 1-9.

14. Pieper M. Entrepreneurial leadership in crowd funded startups and SMEs - A critical incident analysis of entrepreneurs and managers. University of Twente, Faculty of Management and Governance. 2014.

15. Renko M, El-Tarabishy A, Carsrud AL, Brännback, M. Understanding and Measuring 
Entrepreneurial Leadership Style. Journal of Small Business Management. 2015; 53, 54-74.

16. Wakkee I, Elfring T, Monaghan S. Creating entrepreneurial employees in traditional service sectors. International Entrepreneurship and Management Journal. 2010; 6(1): 1-21.

17. De Greef A. Entrepreneurial Leadership and its Effect on the Social Performance of the Organization. A Bachelor Thesis Submitted to the Faculty of Management and Governance, University of Twente, The Netherlands. 2014.

18. Al Mamun A, Ibrahim MD, Yusoff NOB, Fazal SA. Entrepreneurial Leadership, Performance, and Sustainability of Micro-Enterprises in Malaysia. 2018. Sustainability Journal, 10, www.mdpi.com/journal/sustainability. (Accessed on 7-12-2019.

19. Gupta V, MacMillan IC, Surie G. Entrepreneurial leadership: developing and measuring a crosscultural construct. Journal of Business Venturing. 2004; 19(2): 241-260.

20. Supartha WG, Saraswaty AN. The Impact of Entrepreneurial Leadership on Organizational Performance: A Case of Credit Cooperatives in Bali Indonesia. Journal of Engineering and Applied Sciences. 2019; 14(1): 233-241.

21. Vecchio RP. Entrepreneurship and Leadership: Common trends and Common Threads. Human Resource Management Review. 2003; 13(2): 303327.

22. Chen MH. Entrepreneurial Leadership and New Ventures: Creativity in Entrepreneurial Teams. Creativity and Innovation Management. 2007; 16(3): 239-249.

23. Strubler DC, Redekop BW. Entrepreneurial human resource leadership: A conversation with Dwight Carlson. Human Resource Management. 2010 Jul;49(4):793-804.

24. Wang Z, Tchernev JM and Solloway T. A dynamic longitudinal examination of social media use, needs, and gratifications among college students. Computers in Human Behavior.2012; 28(5), 1829-1839.

25. Man TW, Lau T, Snape E. Entrepreneurial Competencies and the Performance of Small and Medium Enterprises: An Investigation through a Framework of Competitiveness. Journal of Small Business and Entrepreneurship. 2008; 21, 257276.

26. Pihie ZAL, Asimiran S, Bagheri A. Entrepreneurial Leadership Practices and School Innovativeness. South African Journal of Education. 2014; 34(1): $1-11$.

27. Obiwuru CT, Okwu AT, Akpa VO, Nwankwere IA. Effects of Leadership Style on Organizational Performance: a survey of selected small scale enterprises in Ikosi-Ketu Council Development Area of Lagos State, Nigeria. Australian Journal of Business and Management Research. 2011; 1(7): 100-111.

28. Tat Keh H, Mai Nguyen T, Ping Ng H. The Effects of Entrepreneurial Orientation and Marketing Information on the Performance of SMEs. Journal of Business Venturing. 2007; 22, 592-611.

29. Hamzah MSG, Yusof BH, Abdullah S. Headmaster and entrepreneurship criteria. European Journal of Social Sciences, 2009; 11(4): 535-543.

30. Ruvio A, Rosenblatt Z, Hertz-Lazarowitz R. Entrepreneurial leadership vision in nonprofit vs. for-profit organizations. The Leadership Quarterly. 2010 Feb 1;21(1):144-58.

31. Freeman D, Siegfried Jr RL. Entrepreneurial leadership in the context of company start- up and growth. Journal of leadership studies. 2015 Feb;8(4):35-9.

32. Musambayi, N. J. Leadership and Firm Entrepreneurial Performance in County Governments in Kenya. Journal of Global Entrepreneurship Research. 2018; 8(31): 1-12. 